\title{
Association between Body Condition and Oxidative Status in Dogs
}

\author{
Anna Pasquini ${ }^{1 *}$, Silvia Roberti ${ }^{1}$, Valentina Meucci $^{1}$, Elena Luchetti ${ }^{1}$, Sergio Canello ${ }^{2}$, \\ Gianandrea Guidetti ${ }^{2}$, Giulia Biagi ${ }^{1}$ \\ ${ }^{1}$ Department of Veterinary Science, University of Pisa, Pisa, Italy; ${ }^{2}$ Sanypet, Bagnoli di Sopra, Padova, Italy. \\ Email: *apasquini@vet.unipi.it
}

Received May $17^{\text {th }}, 2013$; revised June $17^{\text {th }}, 2013$; accepted June $24^{\text {th }}, 2013$

Copyright (C) 2013 Anna Pasquini et al. This is an open access article distributed under the Creative Commons Attribution License, which permits unrestricted use, distribution, and reproduction in any medium, provided the original work is properly cited.

\begin{abstract}
Oxidative Stress (OS) is considered an underlying mechanism by which dysfunctional metabolism occurs in obese subjects but there are still very few studies in canine species. The purpose of this study was to evaluate simultaneously the effects of diet on body weight, oxidative and inflammatory status in a group of 12 adult dogs. The dogs were fed a maintenance diet, integrated with natural antioxidants, for a period of 6 months. At the beginning and the end of the trial, Body Condition Score (BCS) was evaluated and haematological (CBCs, Complete Blood Counts), oxidative parameters (d-ROMs, derivatives of Reactive Oxygen Metabolites; BAP, Biological Antioxidant Potential; Retinol; $\alpha$-tocopherol) and inflammatory parameters (Fibrinogen; CRP, C Reactive Protein) were performed. Significant differences ( $p<0.05)$ emerged about BCS, hematocrit (HCT), number of platelets (PLT), d-ROMs, BAP and retinol while no differences were for $\alpha$-tocopherol, fibrinogen and CRP between the two periods of different diet. In this study, dogs showed an oxidative imbalance documented by the increase in d-ROMs and the reduction of BAP and retinol. Inflammatory parameters don't change in relation to body weight like an alteration of the oxidative status could precede the onset of inflammation. The role of oxidative stress and of integration with antioxidants should be taken into special consideration in the dietary treatment in overweight dogs.
\end{abstract}

Keywords: Canine; Nutrition; Overweight; Oxidative Stress; Antioxidants; Inflammation

\section{Introduction}

In recent years, Oxidative Stress (OS) has been postulated to be an important factor in the pathogenesis and development of lifestyle-related diseases [1]. In aerobic cells, free radicals are constantly produced mostly as Reactive Oxygen Species (ROS). Once produced, free radicals are removed by antioxidant defences including endogenous and exogenous antioxidants. The imbalance between prooxidant and antioxidant defences in favor of prooxidants results in oxidative stress associated with the oxidative modification of biomolecules such as lipids, proteins, and nucleic acids. Alone or in combination with primary etiological factors, free radicals are involved in a pathogenesis of many inflammatory, degenerative and neoplastic diseases $[2,3]$. Recently, the prevalence of obesity has been related to a decrease of the plasma antioxidants [4-6], the accumulation of fat has been related to the increase of oxidative stress markers $[1,4,6]$, the oxi-

"Corresponding author. dative stress has been related to high body mass index (BMI) in human [7] and, finally, obesity has been related to chronic inflammatory status [8]. When caloric intake exceeds energy expenditure, the substrate-induced increase in Krebs cycle activity generates an excess of ROS [8]. Energy imbalances lead to the storage of excess energy in adipocytes, resulting in both hypertrophy and hyperplasia. These processes are associated with abnormalities of adipocyte function, particularly mitochondrial stress and disrupted endoplasmic reticulum function [9]. This adipogenesis implies the differentiation of preadipocytes into mature and secreting adipocytes which release a large number of cytokines, termed "adipokines". In addition, the enlargement of adipocytes by fat storage induces adipose tissue hypoxia and the secretion of high levels of inflammatory cytokines [8]. The activation of inflammatory signaling pathways in turn increases mitochondrial ROS generation [9]. Although oxidative stress is considered the underlying mechanism by which dysfunctional metabolism occurs in obese subjects, there are still 
very few studies both in feline and canine subjects [1012]. The purpose of this study was to evaluate simultaneously the effects of diet on body weight and on the oxidative and inflammatory status in a group of adult dogs.

\section{Materials and Methods}

\subsection{Animals and Experimental Design}

A group of 12 healthy adult German Shepherd dogs, all living together in the same environment, was fed with a maintenance diet (diet A), integrated with natural antioxidants, for a period of 6 months. The amount of feed administered was calculated according to the body weight, in accordance with what is indicated by the manufacturer $(13.5 \mathrm{~g} / \mathrm{Kg}$ bw/day).

The transition to new diet was gradual and occurred in about a week. At the beginning and the end of the trial, every dog was weighed and its BCS was evaluated. In addition, each dog was subjected to a blood sample for the determination of haematological, oxidative and inflammatory parameters. Previously, the same dogs were fed with a different maintenance diet (diet B) for a period of at least 6 months, at the dose of $15 \mathrm{~g} / \mathrm{Kg}$ bw/day.

\subsection{Feed Formulation}

The nutritional values, on the label, of the dry food of the trial (diet A) and of the previous one (diet B), are collected in Tables $\mathbf{1}$ and $\mathbf{2}$.

\subsection{Evaluation of Body Condition Score (BCS)}

The BCS was assessed by a 5-points scale [13].

\subsection{Sampling}

Blood was sampled from each dog, fasted for 12 hours, after a clinic examination, at the end of each period of six months of diet. CBCs were assessed on EDTA blood sample within 1 hour from the sampling. Plasma and serum samples were obtained after centrifugation at $2400 \mathrm{rpm}$ for $10 \mathrm{~min}$ and were stored at $-18^{\circ} \mathrm{C}$ until further analysis.

\subsection{Laboratory Analysis}

To evaluate oxidative and inflammatory status some parameters were assessed: CBCs (Complete Blood Counts), d-ROMs (derivatives of Reactive Oxygen Metabolites), BAP (Biological Antioxidant Potential), Retinol, $\alpha$-to-copherol, Fibrinogen and CRP (C Reactive Protein).

CBCs was determined by IDEXX Lasercyte ${ }^{\mathbb{B}}$ hematology analyser (IDEXX Laboratories, Inc., Westbrook, Maine, USA) that provides complete blood counts including a true five-part white blood cell differential and absolute reticulocyte count. Morphological evaluations of blood cell populations were made through the observation of a peripheral blood smear.

Table 1. Nutritional values of maintainance diet administerred to dogs for 6 months.

\section{DIET A}

\begin{tabular}{|c|c|}
\hline Ingredients & $\begin{array}{l}\text { Corn, fish meal }(20 \%) \text {, processed proteins } \\
\text { of chicken }(14 \%) \text {, poultry fat, beet pulp, } \\
\text { yeast, fish oil, minerals, dried yeast (Bio } \\
\text { MOS), FOS, yucca schidigera }\end{array}$ \\
\hline $\begin{array}{l}\text { Guaranteed } \\
\text { analysis }\end{array}$ & $\begin{array}{c}\text { Moisture } 9 \% \text {, crude protein } 34 \% \text { crude fat } \\
21 \% \text { crude fibre } 2 \% \text {, crude ash } 7 \% \text {, } \\
\text { omega } 3.2 \%, 6.2 \% \text { Omega } 6 .\end{array}$ \\
\hline Additives (/Kg) & $\begin{array}{c}\text { Vitamin A } 15,000 \mathrm{IU} \text {, Vitamin D3 } 1080 \\
\text { IU, Vitamin E } 180 \mathrm{mg}, 1000 \mathrm{mg} \text { choline } \\
\text { chloride, copper chelate of amino acids } \\
\text { hydrate } 20 \mathrm{mg} \text {, DL-methionine } 500 \mathrm{mg}, \\
1500 \mathrm{mg} \text { taurine, L-carnitine } 500 \mathrm{mg}, \\
\text { extract rich in tocopherols natural } 44.3 \\
\text { mg Vitamin A } 15,000 \mathrm{IU}, \text { Vitamin D3 } \\
1080 \mathrm{IU}, \text { Vitamin E } 180 \mathrm{mg}, 1000 \mathrm{mg} \\
\text { choline chloride, copper chelate of amino } \\
\text { acids hydrate } 20 \mathrm{mg}, \text { DL-methionine } 500 \\
\text { mg, } 1500 \mathrm{mg} \text { taurine, L-carnitine } 500 \mathrm{mg} \text {, } \\
\text { extract rich in tocopherols natural } 44.3 \\
\mathrm{mg}\end{array}$ \\
\hline $\begin{array}{c}\text { Natural } \\
\text { ingredients added } \\
(/ \mathbf{k g})\end{array}$ & $\begin{array}{c}\text { Rosmarinus officinalis } 0.84 \mathrm{mg} \\
\text { Grifola frondosa } 270 \mathrm{mg} \\
\text { Curcuma longa } 263 \mathrm{mg} \\
\text { Carica papaya } 151 \mathrm{mg} \\
\text { Punica granatum } 103 \mathrm{mg} \\
\text { Aloe vera } 92 \mathrm{mg} \\
\text { Polygonum L. } 82 \mathrm{mg} \\
\text { Alghe (Haematococcus pluvialis) } 74 \mathrm{mg} \\
\text { Solanum lycopersicum } 25 \mathrm{mg} \\
\text { Vitis vinifera } 19 \mathrm{mg}\end{array}$ \\
\hline $\begin{array}{c}\text { Metabolizable } \\
\text { energy }\end{array}$ & $3.916 \mathrm{kcal} / \mathrm{kg}-16.4 \mathrm{MJ} / \mathrm{kg}$ \\
\hline
\end{tabular}

Table 2. Nutritional values of diet consumed by dogs before the trial for at least 6 months.

\begin{tabular}{|c|c|}
\hline DIET B & \\
\hline Ingredients & $\begin{array}{l}\text { Extruded corn, meat, lard, puffed rice, } \\
\text { corn gluten meal, whole vitamin and } \\
\text { mineral, antioxidant BHT, BHA. }\end{array}$ \\
\hline $\begin{array}{l}\text { Guaranteed } \\
\text { analysis }\end{array}$ & $\begin{array}{c}\text { Crude protein } 28 \% \text {, crude fiber } 4 \% \text {, } \\
\text { moisture } 7 \% \text {, crude fat } 22 \% \text {, crude ash } \\
6 \% \text {, Ca } 1.4 \% \text { P } 1 \%\end{array}$ \\
\hline Additives(/Kg) & $\begin{array}{c}\text { Vitamin A } 15,000 \mathrm{IU} \text {, vit. B12 mg, } \\
\text { vitamin B2 } 4 \mathrm{mg} \text {, vitamin B6 } 2 \mathrm{mg} \text {, } \\
\text { vitamin B12 } 0.01 \mathrm{mg} \text {, vit C } 95 \mathrm{mg} \text {, vitamin } \\
\text { D3 } 400 \mathrm{IU} \text {, vitamin E } 45 \mathrm{mg}, 0.2 \mathrm{mg} \\
\text { vitamin H, vitamin K } 2 \mathrm{mg}, 20 \mathrm{mg} \text { vitamin } \\
\text { PP, pant ac of } 8.5 \mathrm{mg}, 0.5 \mathrm{mg} \text { folic ac Co } \\
0.15 \mathrm{mg}, 100 \mathrm{mg} \mathrm{Fe}, \mathrm{Mg} 30 \mathrm{mg}, 14 \mathrm{mg} \\
\mathrm{Cu}, 0.05 \mathrm{mg} \text { If, Zn } 105 \mathrm{mg} .\end{array}$ \\
\hline $\begin{array}{c}\text { Metabolizable } \\
\text { energy }\end{array}$ & $4.012 \mathrm{kcal} / \mathrm{kg}-16.8 \mathrm{MJ} / \mathrm{kg}$ \\
\hline
\end{tabular}

d-ROMs and BAP plasma concentrations were determined by a spectrophotometric methods (Slim, SEAC, 
Florence, Italy). In the d-ROMs test (Diacron International, Grosseto, Italy), the reactive oxygen metabolites (hydroperoxides primarily) of a biological sample, in the presence of iron released from plasma proteins by an acidic buffer, are able to generate alkoxyl and peroxyl radicals according to the Fenton's reaction. Such radicals, in turn, are able to oxidize an alkyl-substituted aromatic amine (N,N-dietylparaphenylendiamine), thus producing a pink-coloured derivative which is photometrically quantified at $505 \mathrm{~nm}$. The d-ROMs concentration runs directly parallel with colour intensity and is expressed as Carratelli Units (1 CARR U $=0.08 \mathrm{mg}$ hydrogen peroxide/ $\mathrm{dL}$ ). In the BAP test (Diacron International, Grosseto, Italy), the addition of a plasma sample to a coloured solution (thiocyanate) that is obtained by mixing a ferric chloride solution with a thiocyanate derivative solution, causes a colour change. The intensity of the decolouration is measured photometrically at $505 \mathrm{~nm}$ and is proportional to the ability of plasma to reduce ferric ions. The results are expressed as $\mu$ moli/L. The normal reference range in dogs is 56.4 - 91.4 U.CARR and 1440 $3260 \mu \mathrm{moli} / \mathrm{L}$ for d-ROMs and BAP, respectively [14].

$\boldsymbol{\alpha}$-tocopherol and retinol serum concentrations were analysed by HPLC and UV detection using a commercial test kit (Chromsystems Instrument and Chemical Ltd., Munchen, Germany). The HPLC system consisted of a Series 200 Perkin Elmer gradient Pump (Norwalk, CT, USA) coupled to a Series 200 Perkin Elmer variable UV detector (Norwalk, CT, USA), which was set at $325 \mathrm{~nm}$ and $295 \mathrm{~nm}$. HPLC was coupled to a personal computer by using an interface SERIES 600 Perkin Elmer (Norwalk, CT, USA). Integration of peaks was performed through Turbochrome Navigator software (Perkin Elmer, Norwalk, CT, USA). The results were expressed as $\mu \mathrm{g} / \mathrm{mL}$.

Fibrinogen was determined by coagulometric method (Clot2, SEAC, Calenzano, Italy). The quantitative determination of fibrinogen is based on the addition of a relatively large amount of thrombin to diluted citrate plasma, so that the clotting time depends only on the fibrinogen contained in the sample. The assay procedure consists of placing $200 \mu \mathrm{L}$ of 1:10-diluted plasma in a test tube preheated to $37^{\circ} \mathrm{C}$, followed by incubation for 2 minutes at $37^{\circ} \mathrm{C}$, and then adding $200 \mu \mathrm{L}$ of the fibrinogen reagent (preheated to $37^{\circ} \mathrm{C}$ ). Upon the addition of the fibrinogen reagent, the stopwatch was started, and the clotting time was measured. For this assay, the results in seconds must be converted into $\mathrm{mg} / \mathrm{dL}$ using a conversion table supplied with the kit.

CRP was assessed by immunoturbidimetric test (Beckman Coulter s.r.l., Milan, Italy). CRP is an acute phase protein synthesized by the liver in response to the release of inflammatory cytokines such as interleukin-6. The concentration of CRP increases significantly as a result of acute or chronic inflammation observed in the case of bacterial infections (the most powerful stimulus for the CRP production), an autoimmune disease or immune complex, tissue necrosis and malignant tumors, myocardial infarction and trauma. The increase is recorded by 24 to 48 hours and the level can be 2000 times higher than the normal value. In many cases, the changes in plasmatic CRP level are preceding the clinical symptoms. When a sample is mixed with the buffer solution and antiserum solution, the CRP reacts specifically with anti-CRP giving rise to insoluble aggregates. The absorbance of these aggregates is proportional to the concentration of CRP in the sample.

\subsection{Statistical Analysis}

The data were examined for normality on the basis of Kurtosis and Skewness coefficients. t Student test was applied to evidence differences in the investigated parameters, between before and after the trial; Pearson multiple correlation test was applied to measure the strength of the linear relationship between the variables. Results were considered significant at a value of $p<0.05$. Statistical analysis was performed by use of commercial statistical software (STATGRAPHICS Plus ${ }^{\circledR}$, Centurion).

\section{Results}

All the data were normally distributed, except CRP to which has been applied the transformation $\log 10$. Table 3 contains data before and after the administration of diet A. At the beginning of the period, $83 \%$ of dogs showed a BCS greater than 3 while $17 \%$ was attributed a BCS

Table 3. Data $(M \pm S D)$ of analysed parameters before and after the administration of $\operatorname{diet} A$.

\begin{tabular}{ccc}
\hline & Before & After \\
\hline M \pm SD & M \pm SD \\
\hline BCS & $3.6 \pm 0.9$ & $\mathbf{2 . 9} \pm \mathbf{0 . 3}^{*}$ \\
dROMs $(\mathrm{U} . \mathrm{CARR})$ & $102.3 \pm 23.8$ & $\mathbf{4 5 . 6} \pm \mathbf{2 5 . 9 ^ { * * }}$ \\
BAP $(\mu \mathrm{moli} / \mathrm{L})$ & $1602 \pm 111$ & $\mathbf{1 8 7 6} \pm \mathbf{3 5}^{*}$ \\
Retinol $(\mu \mathrm{g} / \mathrm{mL})$ & $0.34 \pm 0.13$ & $\mathbf{0 . 5 5} \pm \mathbf{0 . 1}^{* *}$ \\
Tocopherol $(\mu \mathrm{g} / \mathrm{mL})$ & $32.2 \pm 13.7$ & $21.5 \pm 16.1$ \\
HCT $(\%)$ & $46.3 \pm 3.5$ & $\mathbf{4 2 . 6} \pm \mathbf{3 . 9 ^ { * }}$ \\
PLT $(\mathrm{K} / \mu \mathrm{L})$ & $367 \pm 61$ & $\mathbf{2 4 5} \pm \mathbf{7 5 ^ { * * }}$ \\
Fibrinogen $(\mathrm{mg} / \mathrm{dL})$ & $323 \pm 94$ & $284 \pm 126$ \\
CRP $(\mathrm{mg} / \mathrm{dL})$ & $0.12 \pm 0.08$ & $0.04 \pm 0.07$ \\
\hline
\end{tabular}

Mean values with superscript asterisks differ significantly $\left(^{*} \mathrm{p}<0.05{ }^{* *} \mathrm{p}<\right.$ $0.01)$; LEGEND: BCS, Body Condition Score; d-ROMs, derivatives of Reactive Oxygen Metabolites; BAP, Biological Antioxidant Potential; HCT, hematocrit; PLT, Platelets; CRP, C Reactive Protein. 
slightly less than 3 . At the end of the trial, all of the subjects reached the ideal weight $(\mathrm{p}<0.01)$. All haematological parameters were found to be within the reference range in both controls; in Table 3 have been reported those which showed a significant variation to vary the diet (HCT and PLT). High significant differences have emerged for d-ROMs, Retinol and PLT; significant differences for BCS, BAP and HCT; no differences for $\alpha$ tocopherol, fibrinogen and CRP.

Table 4 report Pearson coefficient values emerged by multiple analysis. A weak negative correlation has emerged between BAP vs d-ROMs and CRP vs HCT; a weak positive correlation between number of lymphocytes vs Retinol; a moderate negative correlation between BCS vs BAP, BAP vs $\alpha$-tocopherol, retinol vs $\alpha$-tocopherol and HCT vs BAP; a moderate positive correlation between BCS vs $\alpha$-tocopherol, BAP vs Retinol and BAP vs number of lymphocytes.

\section{Discussion}

Evidence of obesity-induced oxidative stress in humans has emerged in the past several years, and similar evidence has been demonstrated in pets more recently $[10,11]$. In this study, subjects who were moderate overweight were also in a state of oxidative stress documented by the increase in ROS and the reduction of BAP; at the end of the trial, the recovery of the right weight and of the oxidative balance was detected. In particular, the values of BCS and d-ROMs significantly decreased after the second period of study while BAP and retinol increased. Also HCT and PLT values decreased in this period, even if they always are within referral ranges; in this respect, may be interesting to remember as the number of platelets tends to increase in the course of inflamematory disease. No variations were in fibrinogen and CRP concentrations; these results seem in contrast with the inflammatory condition observed in overweight men $[8,9]$. But they are according to a recent study by Tvari- jonaviciute et al. (2012) in which CRP values didn't vary to body weight changes in dogs affected by metabolic syndrome. An alteration of the oxidative status could precede the onset of inflammation which becomes manifest only at a later stage of obesity both in terms of time and gravity [15].

A mild correlation between weight changes and plasma oxidative parameters alteration was observed; even in the canine species, mechanisms similar to those already documented in humans, in which the alteration between production and removal of radical species occurs in obese subjects, but also in "pre-obesity" condition and in asymptomatic subjects, can be assumed $[1,4,16,17]$. A positive correlation between number of lymphocytes and BAP or $\alpha$-tocopherol is fully consistent with the importance of antioxidants on immunological functions. In that study, senior dogs benefited from added vitamin $\mathrm{E}$ and beta-carotene at raised levels in the diet by improving immune function (higher T-cells proliferation) and lowering markers of inflammation (cytokine profile) and oxidative stress (glutathione) [18].

An adequate diet seems to be crucial both for the maintenance of ideal weight and a good oxidative balance. It was possible to normalize the body weight of the study subjects with a maintenance diet but with certain characteristics such as the protein source, mainly based on fish and therefore rich in omega 3 fatty acids and the presence of FOS, L-carnitin, vitamins and natural antioxidants. Omega- 6 polyunsaturated fatty acids (n-6 PUFA) and omega-3 (n-3 PUFA) are precursors to potent lipid mediator signalling molecules, which have important roles in the regulation of inflammation. In general, eicosanoids derived from n-6 PUFA are proinflammatory while eicosanoids derived from n-3 PUFA are anti-inflammatory. By increasing the ratio of (n-3):(n-6) PUFA in diet, reductions may be achieved in the incidence of chronic inflammatory diseases [19]. A short-chain fructooligosaccharide (FOS) supplementation may modulate

Table 4. Pearson coefficient values showing the correlations between analysed parameters.

\begin{tabular}{|c|c|c|c|c|c|c|c|}
\hline & BCS & dROMs & BAP & retinol & $\alpha$-tocoferol & HCT & Lymph \\
\hline d-ROMs (U.CARR) & 0.0281 & & & & & & \\
\hline BAP $(\mu \mathrm{moli} / \mathrm{L})$ & $0.3465^{* *}$ & $-0.2576^{* *}$ & & & & & \\
\hline $\operatorname{Retinol}(\mu \mathrm{g} / \mathrm{mL})$ & 0.0441 & 0.1984 & 0.0843 & & & & \\
\hline$\alpha$-tocoferol $(\mu \mathrm{g} / \mathrm{mL})$ & $0.3132^{*}$ & -0.2271 & $-0.3673^{* * *}$ & $-0.3870^{* * *}$ & & & \\
\hline HCT (\%) & 0.1189 & -0.0185 & $-0.4335^{* *}$ & 0.0085 & 0.1606 & & \\
\hline Lymph $(\mathrm{K} / \mu \mathrm{L})$ & 0.0873 & 0.0221 & $0.3284^{* *}$ & $0.2936^{*}$ & -0.1668 & -0.2436 & \\
\hline CRP (mg/dL) & -0.1391 & 0.1594 & 0.2288 & -0.0097 & -0.1076 & $-0.2757^{*}$ & 0.0447 \\
\hline
\end{tabular}

Values with superscript asterisks show a significant correlation $\left({ }^{*} \mathrm{p}<0.05,{ }^{* *} \mathrm{p}<0.01\right)$; LEGEND: BCS, Body Condition Score; d-ROMs, derivatives of Reactive Oxygen Metabolites; BAP, Biological Antioxidant Potential; HCT, hematocrit; Lymph, lymphocytes count. 
insulin resistance and glucose homeostasis in dogs [20]. L-carnitine improves nitrogenous retention and modifies the body composition in favor of lean body mass [21]. Vitamins, $\mathrm{A}$ and $\mathrm{E}$ in particular, are the most important exogenous antioxidants that act both as preventive antioxidants that as chain-breakers [22]. Finally, many vegetal flavonoids have antiradical and antinflammatory properties $[23,34]$. The results above discussed can be considered a starting point for further studies aimed at assessing the role of oxidative stress in overweight dogs and the dietary intervention with a particular emphasis on the antioxidant addition.

\section{REFERENCES}

[1] T. Fukui, K. Yamauchi, M. Maruyama, T. Yasuda, M. Kohno and Y. Abe, "Significance of Measuring Oxidative Stress in Lifestyle-Related Diseases from the Viewpoint of Correlation between d-ROMs and BAP in Japanese Subjects," Hypertension Research: Official Journal of the Japanese Society of Hypertension, Vol. 34, No. 9, 2011, pp. 1041-1045.

[2] B. Halliwell, "Antioxidants in Human Health and Disease," Annual Review of Nutrition, Vol. 16, 1996, pp. 33-50. doi:10.1146/annurev.nu.16.070196.000341

[3] V. B. Djordjević, "Free Radicals in Cell Biology," International Review of Cytology, Vol. 237, 2004, pp. 57-89. doi:10.1016/S0074-7696(04)37002-6

[4] K. Kotani and N. Taniguchia, "The Association between Reactive Oxygen Metabolites and Metabolic Syndrome in Asymptomatic Japanese Men," Journal of Clinical Medicine Research, Vol. 3, No. 5, 2011, pp. 247-251.

[5] R. Goyal, M. Singhai and A. F. Faizy, "Glutathione Peroxidase Activity in Obese and Nonobese Diabetic Patients and Role of Hyperglycemia in Oxidative Stress," Journal of Mild-Life Health, Vol. 2, No. 2, 2011, pp. 72-76.

[6] D. Venturini, A. N. Simão, N. A. Scripes, L. D. Bahls, P. A. Melo, F. M. Belinetti, M. A. Lozovoy and I. Dichi, "Evaluation of Oxidative Stress in Overweight Subjects with or without Metabolic Syndrome," Obesity, Vol. 20, No. 12, 2012, pp. 2361-2366. doi:10.1038/oby.2012.130

[7] W. Wonisch, A. Falk, I. Sundl, B. M. Winklhofer-Roob and M. Lindschinger, "Oxidative Stress Increases Continuously with BMI and Age with Unfavourable Profiles in Males," Aging Male, Vol. 15, No. 3, 2012, pp. 159-165. doi:10.3109/13685538.2012.669436

[8] P. Codoñer-Franch, V. Valls-Bellés, A. Arilla-Codoñer and E. Alonso-Iglesias, "Oxidant Mechanisms in Childhood Obesity: The Link between Inflammation and Oxidative Stress," Translational Research: The Journal of Laboratory and Clinical Medicine, Vol. 158, No. 6, 2011, pp. 369-384. doi:10.1016/j.trsl.2011.08.004

[9] Y. B. Tripathi and V. Pandey, "Obesity and Endoplasmic Reticulum (ER) Stresses," Frontiers Inimmunolology, Vol. 3, 2012, p. 240.

[10] A. E. Tanner, J. Martin and K. E. Saker, "Oxidative Stress and Inflammatory State Induced by Obesity in the Heal- thy Feline," Journal of Animal Physiology and Animal Nutrition (Berl.), Vol. 91, No. 3-4, 2007, pp. 163-166. doi:10.1111/j.1439-0396.2007.00680_7.X

[11] R. W. Grant, B. M. Vester Boler, T. K. Ridge, T. K. Graves and K. S. Swanson, "Adipose Tissue Transcriptome Changes during Obesity Development in Female Dogs" Physiological Genomics, Vol. 43, No. 6, 2011, pp. 295-307. doi:10.1152/physiolgenomics.00190.2010

[12] D. J. Laflamme, "Companion Animals Symposium: Obesity in Dogs and Cats: What Is Wrong with Being Fat?" Journal of Animal Science, Vol. 90, No, 5, 2012, pp. 1653-1662. doi:10.2527/jas.2011-4571

[13] A. J. German, S. Holden, G. L. Moxham, K. L. Holmes, R. M. Hackett and J. M. Rawlings, "Simple, Reliable Tool for Owners to Assess the Body Condition of Their Dog or Cat," The Journal of Nutrition, Vol. 136, pp. 2031S2033S.

[14] A. Pasquini, E. Luchetti, V. Marchetti, E. L. Iorio and G. Cardini, "Analytical Performances of d-ROMs Test and BAP Test in Canine Plasma. Definition of the Normal Range in Healthy Labrador Dogs," Veterinary Research Communication, Vol. 32, 2008, pp. 137-143. doi:10.1007/s11259-007-9014-x

[15] A. Tvarijonaviciute, J. J. Ceron, S. L. Holden, D. J. Cuthbertson, V. Biourge, P. J. Morris and A. J. German, "Obesity-Related Metabolic Dysfunction in Dogs: A Comparison with Human Metabolic Syndrome BMC," Veterinary Research, Vol. 8, 2012, p. 147.

[16] I. Bondia-Pons, L. Ryan and J. A. Martinez, "Oxidative Stress and Inflammation Interactions in Human Obesity," Journal of Physiology and Biochemistry, Vol. 68, No. 4, 2012, pp. 701-711. doi:10.1007/s13105-012-0154-2

[17] A. De Lorenzo, V. Del Gobbo, M. G. Premrov, M. Bigioni, F. Galvano and L. Di Renzo, "Normal-Weight Obese Syndrome: Early Inflammation?" American Journal of Clinical Nutrition, Vol. 85, 2007, pp. 40-45.

[18] S. Massimino and M. Hayek, "Effect of Supplemental Dietary Vitamin E and Beta-Carotene on Immune and Oxidative Parameters in Young and Old Beagle Dogs," XVI ESVCP Congress Proceedings, Amsterdam, September 2006, pp. 14-16.

[19] E. Patterson, R. Wall, G. F. Fitzgerald, R. P. Ross and C. Stanton, "Health Implications of High Dietary Omega-6 Polyunsaturated Fatty Acids," Journal of Nutrition and Metabolism, Vol. 2012, p. 16.

http://www.hindawi.com/journals/jnume/2012/539426/

[20] F. Respondek, K. S. Swanson, K. R. Belsito, B. M. Vester, A. Wagner, L. Istasse and M. Diez, "Short-Chain Fructooligosaccharides Influence Insulin Sensitivity and Gene Expression of Fat Tissue in Obese Dogs," Journal of $\mathrm{Nu}$ trition, Vol. 138, 2008, pp. 1712-1718.

[21] K. L. Gross and S. C. Zicker, "L-Carnitine Increases Muscle Mass, Bone Mass, and Bone Density in Growing Large Breed Puppies," Journal of Animal Science, Vol. 78, 2000, p. 176.

[22] B. Halliwell, "Food Derived Antioxidants," In: E. Cadenas and L. Packer, Eds., Handbook of Antioxidants, 2nd Edition, CRC Press, New York, 2002, pp. 1-46.

[23] H. S. Chaudhari, U. Bhandari and G. Khanna, "Preventive 
Effect of Embelin from Embelia Ribes on Lipid Metabolism and Oxidative Stress in High-Fat Diet-Induced Obesity in Rats," Planta Medica, Vol. 78, No. 7, 2012, pp. 651-657. doi:10.1055/s-0031-1298379

[24] G. Kaur and C. Meena, "Amelioration of Obesity, Glucose Intolerance, and Oxidative Stress in High-Fat Diet

\section{Abbreviations}

BAP: Biological Antioxidant Potential;

BCS: Body Condition Score;

BMI: Body Mass Index;

CBCs: Complete Blood Counts;

CRP: C Reactive Protein;

d-ROMs: Derivatives of Reactive Oxygen Metabolites; and Low-Dose Streptozotocin-Induced Diabetic Rats by Combination Consisting of 'Curcumin with Piperine and Quercetin'," ISRN Pharmacology, Vol. 2012, 2012, p. 7. http://www.hindawi.com/isrn/pharmacology/2012/95728 $3 / \mathrm{cta} /$
FOS: Short-Chain Fructooligosaccharides;

HCT: Hematocrit;

OS: Oxidative Stress;

PLT: Platelets;

PUFA: Polyunsaturated Fatty Acids;

ROS: Reactive Oxygen Species. 